\title{
PENENTUAN METODE PEMELIHARAAN DAN PENANGANAN LAPIS PERMUKAAN LENTUR JALAN MENGGUNAKAN METODE PAVEMENT CONDITION INDEX (PCI)
}

\section{Dian Setiawan, Heri Suprapto}

Program Pasca Sarjana Universitas Gunadarma, Jakarta, Indonesia

Email: dianbinamarga@gmail.com, heri_gd@yahoo.com

\begin{abstract}
Abstrak
Jalan yang baik akan berpengaruh baik terhadap kinerja masyarakat, seperti: aktivitas jual beli komoditas pangan oleh masyarakat, keperluan kesehatan masyarakat, pendidikan anak dan lain sebagainya. Dalam mewujudkan jalan yang baik dan nyaman bagi masyarakat, pemerintah tidak hanya membangun jalan, melainkan pemerintah melakukan pemeliharaan jalan terhadap jalan yang mengalami kerusakan. Kebutuhan adanya pemeliharaan pada lapis permukaan lentur untuk mempertahankan kemantapan jalan. Tujuan Penelitian untuk mengetahui jenis dan tingkat kerusakan pada jalan dengan perkerasan lentur dan Menentukan jenis pemeliharaan yang diperlukan sesuai dengan tingkat kerusakan jalan tersebut. Data kerusakan didapatkan dengan pengamatan langsung / visual pada objek penelitian. Oleh karena itu, dibutuhkan suatu data informasi yang dapat membantu dalam memperoleh informasi dan melakukan analisis terhadap jenis penanganan prasarana jalan. Metode yang digunakan untuk menganalisis dan pengambilan keputusan menggunakan Sistem Pavement Condition Index (PCI) dengan menghitung kadar kerusakan (Density), nilai pengurangan (Deduct Value), Total Deduct Value (TDV), Corect Deduct Value (CDV) dan Nilai PCI. Analisa data. Hasil analisa terhadap 7 ruas jalan di kota bogor didapat nilai PCI yang berbeda - beda dan jenis penanganan yang berbeda. Jl. Kencana Nilai PCI 70 jenis pemeliharaan rehabilitas, Jl. Beo Nilai PCI 95 jenis pemeliharaan rutin, Jl. Bincarung nilai PCI 75 jenis pemeliharaan berkala, Jl. Kesehatan nilai PCI 91 Jenis pemeliharaan Rutin, Jl. Kukupu Nilai PCI 59 jenis pemeliharaan berkala, Jl. Pemuda Nilai PCI 89 jenis pemeliharaan rutin, Jl. Puter nilai PCI 28 jenis penanganan rehabilitas. Berdasarkan hasil survey lapangan didapatkan Jenis dan tingkat kerusakan pada ruas jalan tersebut adalah Patching $55 \%$, Potholes 34\%, Alligator Cracking 7\%, Block craking 5\%, LT Cracking 3\%, Depresion 3\%. Berdasarkan nilai PCI yang didapatkan maka persentase Jenis penanganan yang diperlukan sesuai dengan tingkat kerusakan jalan diantaranya Pemeliharaan rutin 43\%, Pemeliharaan berkala 29\%, Pemeliharaan rehabilitas $14 \%$ dan Pemeliharaan Rekontruksi $14 \%$.
\end{abstract}

Kata Kunci: Pavement Condition Index (PCI); jenis pemeliharaan; kerusakan jalan

\begin{tabular}{ll}
\hline How to cite: & Setiawan, D. \& Heri Suprapto (2021). Penentuan Metode Pemeliharaan dan Penanganan Lapis \\
& Permukaan Lentur Jalan Menggunakan Metode Pavement Condition Index (PCI). Syntax Literate: \\
& Jurnal Ilmiah Indonesia, 6(1). \\
E-ISSN: & 2548-1398 \\
Published by: & Ridwan Institute
\end{tabular}

Published by: $\quad$ Ridwan Institute 


\section{Abstract}

Good roads will have a good effect on community performance, such as: buying and selling activities of food commodities by the community, public health needs, children's education and so on. In realizing a good and comfortable road for the community, the government does not only build roads, but the government carries out road maintenance for damaged roads. The need for maintenance on the flexible surface layer to maintain road stability. The purpose of the study was to determine the type and level of damage to the road with flexible pavement and determine the type of maintenance required according to the level of damage to the road. Damage data obtained by direct observation / visual on the object of research. Therefore, we need an information data that can assist in obtaining information and analyzing the types of road infrastructure handling. The method used to analyze and make decisions using the Pavement Condition Index (PCI) System by calculating the level of damage (Density), Deduct Value (Deduct Value), Total Deduct Value (TDV), Correct Deduct Value (CDV) and PCI Value. Data analysis The results of the analysis of 7 roads in the city of Bogor obtained different PCI values and different types of handling. Jl. Kencana Value PCI 70 types of rehabilitation maintenance, $\mathrm{Jl}$. Parrots PCI Value 95 types of routine maintenance, Jl. Bincarung PCI value 75 type of periodic maintenance, Jl. Health PCI score 91 Type of routine maintenance, Jl. Butterfly PCI Value 59 types of periodic maintenance, Jl. Youth PCI Value 89 types of routine maintenance, Jl. Puter PCI value 28 type of rehabilitation treatment. Based on the results of the field survey, it was found that the type and level of damage to these roads were Patching 55\%, Potholes 34\%, Alligator Cracking 7\%, Block cracking 5\%, LT Cracking 3\%, Depression 3\%. Based on the PCI value obtained, the percentage of types of handling required according to the level of road damage include routine maintenance $43 \%$, periodic maintenance $29 \%$, rehabilitation maintenance $14 \%$ and reconstruction maintenance $14 \%$.

Keywords: pavement condition index (PCI); type of maintenance; road damage

Received: 2021-10-20; Accepted: 2021-11-05; Published: 2021-11-18

\section{Pendahuluan}

Infrastruktur merupakan bagian yang penting dari kehidupan suatu Negara. Infrastruktur menjadi kebutuhan dasar fisik dalam mengatur sistem yang dibutuhkan negara. Perekonomian suatu negara dapat berjalan dengan baik ketika memiliki infrastruktur yang baik. Infrastruktur yang baik berperan dalam penjaminan ekonomi pada sektor privat maupun publik dan dalam hal fasilitas yang dibutuhkan. Infrastruktur meliputi infrastruktur keras, infrastruktur keras nonfisik, dan infrastruktur lunak.

Dalam Laporan Daya Saing Global di tahun 2019, yang disusun oleh World Economic Forum (WEF), Indonesia dalam hal pembangunan infrastruktur menduduki peringkat 72 dari 141 negara. Laporan tersebut membuktikan bahwa pembangunan infrastruktur di Indonesia memerlukan perhatian lebih. Negara yang memiliki penduduk lebih dari 200 juta ini masih perlu meningkatkan pembangunan infrastruktur. Terlebih, 
pembangunan infrastruktur pada suatu negara dapat membantu negara tersebut untuk mencapai potensi penuh dalam pertumbuhan ekonomi.

Kebutuhan tersebut di atas membuat pemerintah terus meningkatkan daya dalam pembangunan infrastruktur. .Dikutip dari portal berita CNBC Indonesia, sejak awal pemerintahan Joko Widodo (Jokowi) sebagai Presiden, pemerintah terus melancarkan pembangunan infrastruktur. Di tahun 2019, angka belanja infrastruktur Indonesia mencapai Rp 420 triliun. Angka ini meningkat sebesar 157\% dari tahun 2014 yang hanya sebesar Rp 163 triliun. Adapun pembangunan infrastruktur yang dibangun pemerintah adalah sebagai berikut: bendungan, irigasi, jalan tol, jembatan, jembatan gantung, sistem penyediaan air minum, perumahan, penanganan kawasan kumuh perkotaan, sanitasi, pembangunan pos lintas batas negara, rumah susun, rumah khusus, rumah swadaya, dan jalan.

Penelitian terdahulu yang melatarbelakangi saya diantaranya (Sari, 2015), melakukan penelitian dengan judul "Perbandingan Nilai Kerusakan Jalan Berdasarkan Pengamatan Metode PCI (Pavement Condition Index) dan Metode IRI (International Roughness Index) pada Jalan Kelas II di Kabupaten Lumajang. Dalam penelitian ini peneliti Menghitung dan membandingkan nilai Pavement Condition Index (PCI) dengan International Roughness Index (IRI)

(Evitya, Nasfryzal, \& Zufrimar, 2020) judul penelitian "Analisa Kerusakan Perkerasan Jalan dengan Metode Pavement Condition Index (PCI) dan Bina Marga (Studi Kasus : Ruas Jalan Sijunjung Sta 103+000-108+000), dimensi, jenis-jenis dan tingkat kerusakan pada ruas jalan tersebut. Penelitian dilakukan dengan cara survei untuk mendapatkan data primer sehingga dapat dijadikan acuan untuk penanganan pemeliharaan perkerasan jalan. Metode yang digunakan adalah metode PCI (pavement condition index) dan metode Bina Marga.

(Giyatno \& Sunarjono, 2016), melakukan penelitian dengan judul “Analisis Kerusakan Jalan dengan Metode PCI Kajian Ekonomis dan Strategi Penanganannya ( Studi Kasus Ruas Jalan Ponorogo - Pacitan KM 231 + 000 sampai dengan KM 246 +000, KM 0+000 di Surabaya). Peneliti menggunakan metode PCI untuk mengetahui tipe kerusakan, tingkat keparahan kerusakan, dan jumlah atau kerapatan kerusakan.

(Hasibuan, 2018), melakukan penelitian dengan judul Änalisa Kerusakan pada Lapisan Jalan Perkerasan Rigid dengan metode Binamarga dan metode PCI (Pavement Condition Index). Peneliti Menganalisa kondisi struktur perkerasan jalan sangat diperlukan sebelumdilakukannya perawatan dan perbaikan. Duametode yang dapat digunakan dalammelakukan penilaian kondisi jalan adalah metode Bina Marga dan metode PCI(Pavement Condition Index).

(Mubarak, 2016), Analisa Tingkat Kerusakan Perkerasan Jalan Dengan Metode Pavement Condition Index (Pci) Studi Kasus : Jalan Soekarno Hatta Sta. $11+150$ s.d $12+150$ ”. Analisa Kerusakan Perkerasan Jalan Dengan Metode Pavement Condition Index (PCI) (Studi “Kasus: Jalan Soekarno Hatta Pekanbaru Sta. 11+150 s/d 12+150) sistem penilaian kondisi perkerasan jalan berdasarkan jenis, tingkat dan kadar kerusakan 
yang terjadi, dan dapat digunakan sebagai acuan dalam usaha pemeliharaan perkerasan jalan.

Tercantum dalam Peraturan Menteri Pekerjaan Umum No. 13 Tahun 2011, pemeliharaan jalan merupakan kegiatan penanganan jalan, berupa pencegahan, perawatan dan perbaikan yang diperlukan untuk mempertahankan kondisi jalan. Pemeliharaan tersebut dilakukan agar jalan tetap berfungsi secara optimal melayani lalu lintas, sehingga umur rencana yang ditetapkan dapat tercapai. Beberapa daerah di Indonesia memiliki beberapa kasus dalam kerusakan jalan yang perlu dilakukan pemeliharaan jalan. Salah satu daerah tersebut adalah yang diambil penelitian oleh penulis, yakni beberapa ruas jalan di Kecamatan Tanah Sareal Kota Bogor Provinsi Jawa Barat. Daerah tersebut memiliki beberapa kasus kerusakan jalan yang perlu ditangani, seperti : kondisi jalan yang retak, licin, mengelupas, bergelombang, dan berlubang. Kasus kerusakan jalan tersebut berada di beberapa titik di Kecamatan Tanah Sareal Kota Bogor. Sedangkan, pemerintah daerah setempat melakukan pemeliharaan jalan secara bergantian dan tidak bersamaan. Pemda akan melakukan pemeliharaan terhadap jalan yang diprioritaskan untuk dipelihara.

Jalan sebagai salah satu prasarana transportasi yang menyangkut hajat hidup orang banyak, mempunyai fungsi sosial yang sangat penting. Dengan pengertian tersebut wewenang penyelanggaraan jalan wajib dilaksanakan dengan mengutamakan sebesar - besar kepentingan umum.

Berdasarkan KeputusanWalikota Bogor Nomor : 620.45-34 Tahun 2016 Tentang Penetapan Ruas - Ruas Jalan di Kota Bogor Menurut statusnya sebagai Jalan Kota, panjang ruas jalan kota di Kota Bogor menjadi 717,385 Km yang dirinci ke dalam 2.046 ruas yang tersebar di 6 Kecamatan. Mengingat banyaknya ruas jalan yang harus ditangani oleh Pemerintah Kota Bogor sedangkan dana yang tersedia untuk penanganan jalan sangat terbatas, maka diperlukan prioritas penanganan ruas jalan kota agar alokasi anggaran menjadi efektif bagi pembangunan dan pengembangan Kota Bogor

Permasalahan pelaksanaan penanganan jalan kota di Kota Bogor, banyak terjadi ketimpangan - ketimpangan, seperti banyaknya jalan yang belum mendapat penanganan baik pemeliharaan maupun peningkatan.

Perencanaan pembangunan daerah khususnya di bidang infrastruktur transportasi juga belum optimal. Aspirasi masyarakat melalui Musyawarah Perencanaan Pembangunan (Musrenbang) ditingkat kelurahan dan kecamatan hanya sebagian kecil yang direalisasikan dalam APBD. Belum adanya penentuan skala prioritas sehingga masih didominasi kebijaksanaan pengambil keputusan untuk kepentingan pihak - pihak tertentu dalam menetapkan kebijakan, yaitu masih memprioritaskan penanganan proyek jalan dengan mengesampingkan kriteria teknis, manfaat dan biaya yang mengakibatkan kesulitan dalam menyusun daftar penanganan ruas jalan.

Keterbatasan data dan informasi terutama yang akurat merupakan salah satu kendala yang dihadapi. Oleh karena itu, dibutuhkan suatu system informasi yang dapat membantu dalam memperoleh informasi dan melakukan analisis terhadap penanganan prasarana jalan. Adapun metode yang digunakan untuk penentuan prioritas penanganan 
jalan dalam penelitian ini adalah metode yang digunakan untuk menganalisis dan pengambilan keputusan menggunakan Sistem Pavement Condition Index (PCI).

\section{Metode Penelitian}

\section{Teknik Pengumpulan Data}

\section{1) Data Primer}

Data primer merupakan data yang didapat secara langsung. Dari penelitian ini, data primer akan didapat dari survei lokasi/terjun ke lapangan tepatnya di lokasi 7 ruas jalan tersebut sesuai dengan perumusan masalah sebelumnya. Data primer inipun akan dilakukan dengan cara pengukuran dan dokumentasi. Hal ini akan diperlukan untuk mengetahui jenis kerusakan jalan pada lokasi tersebut. Setelah menentukan jenis kerusakan, penulis juga akan mengukur ketebalan kerusakan jalan tersebut dengan menggunakan meter. Pengamatan ini akan dilakukan terkait dengan kerusakan jalan antara lain panjang, tinggi, lebar, dan kedalaman dari kerusakan jalan. Data primer yang digunakan dalam penelitian ini yaitu:

a. Observasi

Observasi merupakan suatu proses pengamatan yang digunakan untuk mengamati objek yang akan diteliti. Sehingga peneliti melakukan suvei pada tempat yang akan diteliti yaitu Jalan Raya Kencana Kecamatan Tanah Sareal. Pada observasi yang dilakukan, peneliti melakukan pengamatan pada tiap kerusakan jalan yaitu pada tinggi, lebar, panjang, dan kedalaman dari tiap kerusakan jalan tersebut.

b. Dokumentasi

Dokumentasi merupakan suatu proses kegiatan dokumentasi untuk mendapatkan data berupa foto/gambar yang dilakukan oleh peneliti. Dokumentasi yang akan dilakukan pada tiap jenis kerusakan jalan yang ada pada 7 ruas jalan.

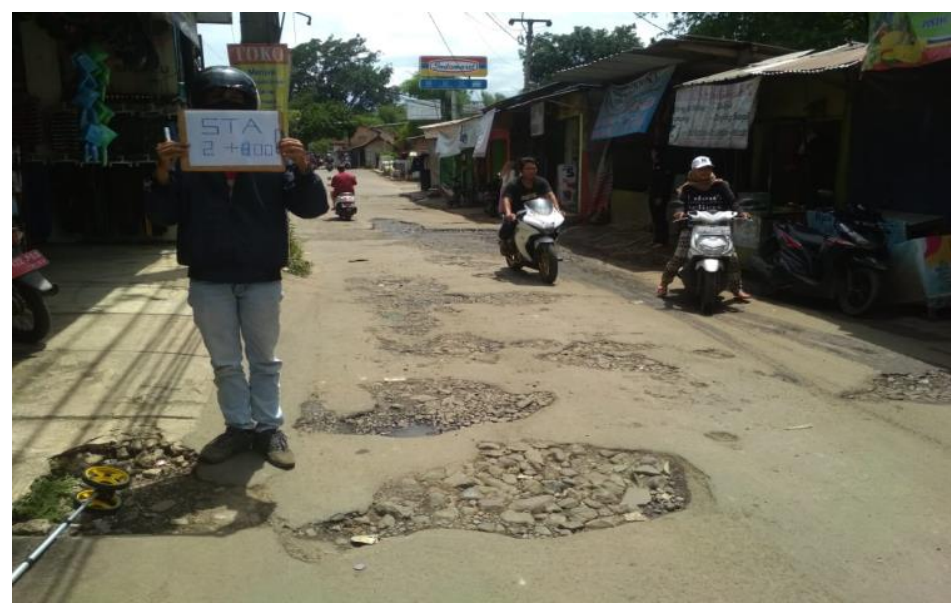

Gambar 1

Foto Survey STA $2+800$ Jl. Kencana 


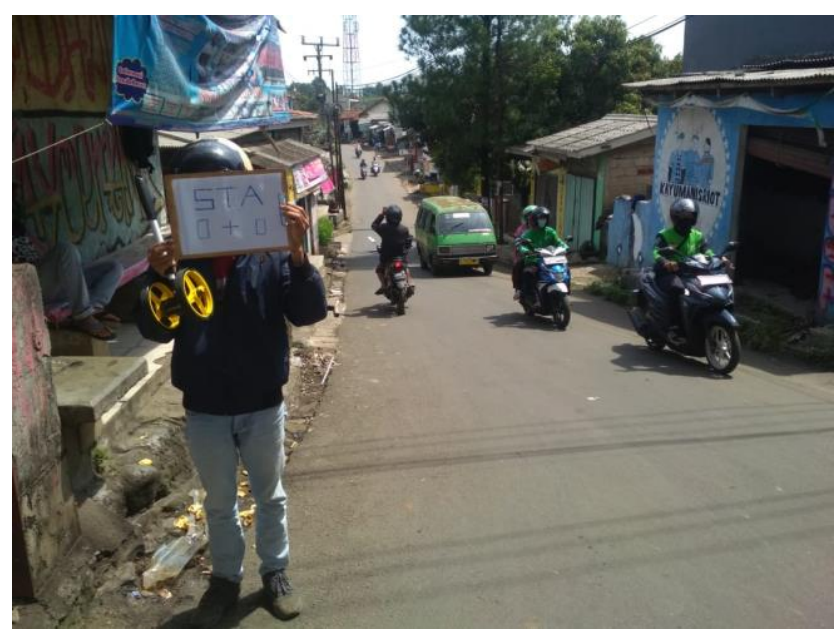

Gambar 2

Foto Survey STA $0+000$ Jl. Kencana

c. Pengukuran Jalan

Pengukuran jalan merupakan suatu kegiatan yang dilakukan dengan menggunakan meteran pada ukuran panjang $50 \mathrm{~m}$. pengukuran ini dilakukan pada jenis kerusakan jalan yang akan diukur adalah ketebalan kerusakan jalan, panjang kerusakan jalan, lebar kerusakan jalan, beda tinggi kerusakan jalan.

\section{2) Data Sekunder}

Data sekunder adalah data yang di dapat dari jurnal-jurnal atau buku-buku yang berkaitan tentang perkerasan jalan. Menurut Shanhin (1994) menyatakan bahwa data sekunder adalah data yang telah tersusun dalam bentuk dokumendokumen, dimana peneliti tidak banyak berbuat untuk menjamin mutu dan peneliti harus mengikuti alur dari data tersebut. Data sekunder didapat dari buku, e-book, jurnal, atau literature lainnya. Dapat dilihat pada tabel 3.1 Review Jurnal.

\section{Hasil dan Pembahasan}

\section{Hasil Analisis}

Dari hasil pengamatan visual dari lapangan diperoleh luas kerusakan, panjang kerusakan, lebar kerusakan, tebal kerusakan, dan kedalaman kerusakan yang nantinya akan menentukan kelas dari berbagai tingkat kerusakan jalan. Densitas kerusakan ini didapat setelah melakukan pengukuran dari tiap jenis kerusakan dan luas kerusakan jalan dari seluruh segmen yang ditinjau. Density (kerapatan) dapat segera dihitung.

Penentuan deduct value dapat diperoleh setelah mendapat hasil kelas kerusakan dan density. Setelah itu, Total Deduct Velue dan Corrected Deduct Value dapat dihitung setelah mendapatkan hasil density. Setelah mendapatkan nilainilai tersebut maka langkah selanjutnya adalah menentukan nilai Pavement Condition Index (PCI). Adapun langkah-langkah perhitungan dengan menggunakan metode PCI adalah sebagai berikut: 
1) Membuat peta kerusakan jalan Peta kerusakan jalan dibuat berdasarkan survey sehingga diperoleh luas, kedalaman ataupun lebar retak yang nantinya dipergunakan untuk menentukan kedalaman ataupun lebar retak yang nantinya dipergunakan untuk menentukan kelas kerusakan.

2) Membuat catatan kondisi dan kerusakan jalan Catatan kondisi dan kerusakan jalan berupa table yang diisi jenis, dimensi, tingkat, dan lokasi terjadinya kerusakan. Catatan ini merupakan catatan berupa dokumentasi dari kondisi jalan oada masing-masing segmen. Masing- masing segmen memiliki ukuran $100 \mathrm{~m} / \mathrm{segmen}$.

3) Memasukkan nilai-nilai catatan Kondisi jalan dan hasil dari penelitian kedalam formulir survey untuk dapat diperhitungkan. Sehingga memudahkan penulis untuk menghitung disetiap segmen.

4) Menentukan nilai pengurangan (deduct value)

\section{Teknik Pemeliharaan atau Penanganan Kerusakan Jalan}

Dalam melakukan kegiatan perbaikan jalan atau melakukan kegiatan penanganan kerusakan jalan sesuai tingkat kerusakan jalan dengan berdasarkan tingkat kerusakan yang berbeda-beda. Dalam metode Pavement Condition Index acuan untuk mengambil keputusan penanganan terhadap kerusakan berdasarkan pada penilaian Pavement Condition Index. Berdasarkan penilaian yang dilakukan, untuk Rating Pavement Condition Index yang berkisar antara 0-25 dilakukan dengan cara penanganan rekonstruksi pada perkerasan jalan, untuk Rating Pavement Condition Index yang berkisaran antara 25-55 dilakukan penanganan rehabilitas pada perkerasan jalan tersebut, sedangkan untuk penanganan yang berkisaran 55-100 dilakukan pemeliharaan rutin. Pemeliharaan jalan merupakan penanganan jalan yang meliputi perawatan, rehabilitasi, penunjangan, dan peningkatan. Adapun jenis pemeliharaan jalan ditinjau dari waktu pelaksanaan adalah:

1) Pemeliharaan Rutin

Pemeliharaan rutin merupakan penanganan yang diberikan hanya pada lapis permukaan yang sifatnya untuk meningkatkan kualitas berkendara (Riding Quality), tanpa meningkatkan kekuatan struktural, dan dilakukan sepanjang tahun. Pemeliharaan rutin yang dilakukan pada bagian ruas jalan memiliki kriteria sebagai berikut:

a. Ruas jalan dengan kondisi baik dan sedang atau disebut jalan mantap.

b. Bangunan pelengkap jalan yang memiliki kondisi jalan yang baik dan baik sekali.

2) Pemeliharaan berkala

Pemeliharaan berkala merupakan pemeliharaan yang dilakukan terhadap jalan pada waktu-waktu tertentu (tidak terus menurus sepanjang tahun) dan sifatnya meningkatkan kekuatan struktural. Adapun kriteria dalam pemeliharaan jalan yaitu sebagai berikut: 
a. Ruas jalan mengalami kerusakan yang lebih luas maka perlu dilakukan pencegahan. Kerusakan ini terjadi karena beban lalu lintas.

b. Ruas jalan mengalami kerusakan karena sudah masuk dalam waktu segmen umur rencana.

c. Bangunan pelengkap yang sudah mempunyai umur pelayanan 3 tahun sampai dengan 5 tahun yang memerlukan penanganan rehabilitasi dan perbaikan besar dalam elemen strukturalnya.

d. Ruas jalan dalam kondisi ringan.

e. Bangunan pelengkap yang memiliki kondisi yang sedang.

3) Peningkatan jalan

Peningkatan jalan merupakan penanganan jalan guna memperbaiki pelayanan jalan yang berupa peningkatan structural dan atau pelayanan yang direncanakan. Adapun kriteria pada peningkatan jalan yaitu:

a. Bangunan pelengkap jalan berupa jembatan, terowongan, lintas atas, lintas bawah, tembok penahan, gorong-gorong dengan kemampuan memikul beban yang sudah tidak memenuhi standar perlu dilakukan perkuatan atau penggantian.

b. Pelengkap yang sudah mempunyai umur pelayanan 3 tahun sampai dengan 5 tahun yang memerlukan penanganan rehabilitasi dan perbaikan besar dalam elemen strukturalnya.

c. Ruas jalan yang awalnya ditangani dengan program pemeliharaan rutin namun, karena suatu sebab mengalami kerusakan yang tidak dipertimbangkan dalam desain.

\section{Urutan Prioritas}

Berdasarkan hasil penelitian didapat rating Pavement Condition Index pada setiap ruas jalan sehingga dapat ditentukan penentuan urutan ruas jalan yang harus diprioritaskan. Untuk lebih jelasnya dapat dilihat pada tabel 1.

Tabel 1

Tabel prioritas Jl. Kencana

\begin{tabular}{cccc}
\hline No & STA & PCI & Rating \\
\hline 1 & $0+000$ s.d $0+400$ & 26 & Poor \\
\hline 2 & $0+400$ s.d $0+800$ & 90 & Excelent \\
\hline 3 & $0+800$ s.d $1+200$ & 90 & Excelent \\
\hline 4 & $1+200$ s.d $1+600$ & 91 & Excelent \\
\hline 5 & $1+600$ s.d $2+000$ & 35 & Poor \\
\hline 6 & $2+000$ s.d $2+400$ & 74 & Very Good \\
\hline 7 & $2+400$ s.d $2+800$ & 84 & Very Good \\
\hline
\end{tabular}

Berdasarkan dari hasil penelitian yang dilakukan maka dapat diketahui nilai nilai yang didapat dalam setiap segmen berbeda-beda. Nilai rating dapat diketahui bahwa semakin rendah nilai rating maka akan semakin jelek kondisi kerusakannya. Uraian diatas menjelaskan bahwa dari 7 segmen dengan ukuran 400m/segmen memiliki nilai PCI yang berbeda-beda. Nilai PCI yang paling rendah yaitu nilai PCI 
26 pada STA 0+400 (segmen 1) dan STA 2+000 (segmen 5). Dan adapun nilai tertinggi yaitu nilai 91 pada STA $1+600$.

\section{Tabel 2}

Tabel prioritas Jl. Bincarung

\begin{tabular}{cccc}
\hline No & STA & PCI & Rating \\
\hline 1 & $0+000$ s.d $0+100$ & 72 & Good \\
\hline 2 & $0+100$ s.d $0+200$ & 100 & Excellent \\
\hline 3 & $0+200$ s.d $0+300$ & 100 & Excellent \\
\hline 4 & $0+300$ s.d $0+400$ & 30 & Poor \\
\hline
\end{tabular}

Uraian diatas menjelaskan bahwa dari 4 segmen dengan ukuran $100 \mathrm{~m}$ /segmen memiliki nilai PCI yang berbeda-beda. Nilai PCI yang paling rendah yaitu nilai PCI 30 pada STA 0+400 (segmen 4). Dan adapun nilai tertinggi yaitu nilai 100 pada STA $0+200$ dan $0+300$.

\section{Tabel 3}

Tabel prioritas Jl. Beo

\begin{tabular}{cccc}
\hline No & STA & PCI & Rating \\
\hline 1 & $0+000$ s.d $0+100$ & 90 & Excellent \\
\hline 2 & $0+100$ s.d $0+200$ & 100 & Excellent \\
\hline 3 & $0+200$ s.d $1+334$ & 94 & Excellent \\
\hline
\end{tabular}

Uraian diatas menjelaskan bahwa dari 3 segmen dengan ukuran $100 \mathrm{~m}$ /segmen memiliki nilai PCI yang berbeda-beda. Nilai PCI yang paling rendah yaitu nilai PCI 90 pada STA $0+100$ (segmen 1). Dan adapun nilai tertinggi yaitu nilai 100 pada STA $0+200$ dan $0+334$.

\section{Tabel 4}

Tabel prioritas Jl. Kesehatan

\begin{tabular}{cccc}
\hline No & STA & PCI & Rating \\
\hline 1 & $0+000$ s.d $0+100$ & 100 & Excellent \\
\hline 2 & $0+100$ s.d $0+200$ & 90 & Excellent \\
\hline 3 & $0+200$ s.d $1+325$ & 84 & Very Good \\
\hline
\end{tabular}

Uraian diatas menjelaskan bahwa dari 3 segmen dengan ukuran $100 \mathrm{~m} / \mathrm{segmen}$ memiliki nilai PCI yang berbeda-beda. Nilai PCI yang paling rendah yaitu nilai PCI 84 pada STA 0+100 (segmen 3). Dan adapun nilai tertinggi yaitu nilai 100 pada STA $0+100$.

Tabel 5

Tabel prioritas Jl. Kukupu

\begin{tabular}{cccc}
\hline No & STA & PCI & Rating \\
\hline 1 & $0+000$ s.d $0+100$ & 16 & Very Poor \\
\hline 2 & $0+100$ s.d $0+200$ & 100 & Excellent \\
\hline 3 & $0+200$ s.d $0+300$ & 20 & Very Poor \\
\hline 4 & $0+300$ s.d $0+530$ & 100 & Excellent \\
\hline
\end{tabular}


Uraian diatas menjelaskan bahwa dari 4 segmen dengan ukuran $100 \mathrm{~m}$ /segmen memiliki nilai PCI yang berbeda-beda. Nilai PCI yang paling rendah yaitu nilai PCI 16 pada STA 0+100 (segmen 1). Dan adapun nilai tertinggi yaitu nilai 100 pada STA $0+200$.

\section{Tabel 6}

Tabel prioritas Jl. Pemuda

\begin{tabular}{cccc}
\hline No & STA & PCI & Rating \\
\hline 1 & $0+000$ s.d $0+100$ & 79 & Very Good \\
\hline 2 & $0+100$ s.d $0+200$ & 100 & Excelent \\
\hline 3 & $0+200$ s.d $0+300$ & 90 & Excelent \\
\hline 4 & $0+300$ s.d $0+400$ & 90 & Excelent \\
\hline 5 & $0+400$ s.d $0+500$ & 82 & Very Good \\
\hline 6 & $0+500$ s.d $0+600$ & 94 & Excelent \\
\hline 7 & $0+600$ s.d $0+700$ & 93 & Excelent \\
\hline 8 & $0+700$ s.d $0+800$ & 89 & Excelent \\
\hline 9 & $0+800$ s.d $0+900$ & 70 & Good \\
\hline 10 & $0+900$ s.d $1+000$ & 100 & Excelent \\
\hline 11 & $1+000$ s.d $1+250$ & 100 & Excelent \\
\hline
\end{tabular}

Uraian diatas menjelaskan bahwa dari 11 segmen dengan ukuran $100 \mathrm{~m}$ /segmen memiliki nilai PCI yang berbeda-beda. Nilai PCI yang paling rendah yaitu nilai PCI 70 pada STA 0+800 (segmen 9). Dan adapun nilai tertinggi yaitu nilai 100 pada STA $0+200$.

Tabel 7

Tabel prioritas Jl. Puter

\begin{tabular}{cccc}
\hline No & STA & PCI & Rating \\
\hline 1 & $0+000$ s.d $0+130$ & 28 & Very Poor \\
\hline
\end{tabular}

Nilai PCI rendah pada ruas jalan Puter.

\section{Jenis Pemeliharaan}

Berdasarkan hasil penelitian, setelah dilakukan analisa menggunakan metode PCI terhadap jenis jenis kerusakan jalan yang ada pada 7 ruas jalan memiliki tingkat kerusakan dan jenis pemeliharaan yang berbeda yaitu sebagai berikut:

1) Ruas Jalan Raya Kencana dengan jarak ukur 3000 m. Pada setiap segmen dengan ukuran $400 \mathrm{~m} / \mathrm{segmen}$.

Tabel 8

Tabel jenis Pemeliharaan Jalan kencana

\begin{tabular}{cccc}
\hline No & STA & PCI & Jenis Pemeliharaan \\
\hline 1 & $0+000$ s.d $0+400$ & 26 & Pemeliharaan Rehabilitas \\
\hline 2 & $0+400$ s.d $0+800$ & 90 & Pemeliharaan Rutin \\
\hline 3 & $0+800$ s.d $1+200$ & 90 & Pemeliharaan Rutin \\
\hline 4 & $1+200$ s.d $1+600$ & 91 & Pemeliharaan Rutin \\
\hline 5 & $1+600$ s.d $2+000$ & 35 & Pemeliharaan Rehabilitas \\
\hline 6 & $2+000$ s.d $2+400$ & 74 & Pemeliharaan Berkala \\
\hline 7 & $2+400$ s.d $2+800$ & 84 & Pemeliharaan Berkala \\
\hline
\end{tabular}


Dengan nilai PCI keseluruhan 490/7 = 70 sehingga jenis penanganan untuk ruas jalan Kencana adalah pemeliharaan rehabilitas dengan kondisi jalan baik (good).

2) Ruas Jalan Beo dengan jarak ukur $334 \mathrm{~m}$. Pada setiap segmen dengan ukuran $100 \mathrm{~m} / \mathrm{segmen}$.

Tabel 9

Tabel Jenis Pemeliharaan jalan Beo

\begin{tabular}{cccc}
\hline No & STA & PCI & Jenis Pemeliharaan \\
\hline 1 & $0+000$ s.d $0+100$ & 90 & Pemeliharaan Rutin \\
\hline 2 & $0+100$ s.d $0+200$ & 100 & Pemeliharaan Rutin \\
\hline 3 & $0+200$ s.d $1+334$ & 94 & Pemeliharaan Rutin \\
\hline
\end{tabular}

Dengan nilai PCI keseluruhan 284/3 = 94,7 sehingga jenis penanganan untuk ruas jalan Kencana adalah pemeliharaan rutin dengan kondisi jalan sempurna (Excelent).

3) Ruas Jalan Bincarung dengan jarak ukur 400 m. Pada setiap segmen

Tabel 10

Tabel jenis Pemeliharaan Jalan Bincarung

\begin{tabular}{cccc}
\hline No & STA & PCI & Jenis Pemeliharaan \\
\hline 1 & $0+000$ s.d $0+100$ & 72 & Pemeliharaan Berkala \\
\hline 2 & $0+100$ s.d $0+200$ & 100 & Pemeliharaan Rutin \\
\hline 3 & $0+200$ s.d $0+300$ & 100 & Pemeliharaan Rutin \\
\hline 4 & $0+300$ s.d $0+400$ & 30 & $\begin{array}{c}\text { Pemeliharaan } \\
\text { Rehabilitas }\end{array}$ \\
\hline
\end{tabular}

Dengan nilai PCI keseluruhan 302/4 = 75,5 sehingga jenis penanganan untuk ruas jalan Bincarung adalah pemeliharaan berkala dengan kondisi jalan sangat baik (Very good).

4) Ruas Jalan Kesehatan dengan jarak ukur 325 m. Pada setiap segmen dengan ukuran $100 \mathrm{~m} / \mathrm{segmen}$.

Tabel 11

Tabel jenis Pemeliharaan jalan Kesehatan

\begin{tabular}{cccc}
\hline No & STA & PCI & Jenis Pemeliharaan \\
\hline 1 & $0+000$ s.d $0+100$ & 100 & Pemeliharaan Rutin \\
\hline 2 & $0+100$ s.d $0+200$ & 90 & Pemeliharaan Rutin \\
\hline 3 & $0+200$ s.d $1+325$ & 84 & Pemeliharaan Berkala \\
\hline
\end{tabular}

Dengan nilai PCI keseluruhan 274/3 = 91,3 sehingga jenis penanganan untuk ruas jalan Kesehatan adalah pemeliharaan rutin dengan kondisi jalan Sempurna (Excelent).

5) Ruas Jalan Kukupu dengan jarak ukur 530 m. Pada setiap segmen dengan ukuran $100 \mathrm{~m} / \mathrm{segmen}$. 
Tabel 12

Tabel Jenis Pemeliharaan Jalan Kukupu

\begin{tabular}{cccc}
\hline No & STA & PCI & Jenis Pemeliharaan \\
\hline 1 & $0+000$ s.d $0+100$ & 16 & Rekontruksi \\
\hline 2 & $0+100$ s.d $0+200$ & 100 & Pemeliharaan Rutin \\
\hline 3 & $0+200$ s.d $0+300$ & 20 & Rekontruksi \\
\hline 4 & $0+300$ s.d $0+530$ & 100 & Pemeliharaan Rutin \\
\hline
\end{tabular}

Dengan nilai PCI keseluruhan 236/4 = 59 sehingga jenis penanganan untuk ruas jalan Kukupu adalah pemeliharaan rehabilitas dengan kondisi jalan baik (Good).

6) Ruas Jalan Pemuda dengan jarak ukur $1250 \mathrm{~m}$. Pada setiap segmen dengan ukuran $100 \mathrm{~m} / \mathrm{segmen}$.

Tabel 13

Tabel Jenis Pemeliharaan Jalan Pemuda

\begin{tabular}{cccc}
\hline No & STA & PCI & Jenis Pemeliharaan \\
\hline 1 & $0+000$ s.d $0+100$ & 79 & Pemeliharaan Berkala \\
\hline 2 & $0+100$ s.d $0+200$ & 100 & Pemeliharaan Rutin \\
\hline 3 & $0+200$ s.d $0+300$ & 90 & Pemeliharaan Rutin \\
\hline 4 & $0+300$ s.d $0+400$ & 90 & Pemeliharaan Rutin \\
\hline 5 & $0+400$ s.d $0+500$ & 82 & Pemeliharaan Berkala \\
\hline 6 & $0+500$ s.d $0+600$ & 94 & Pemeliharaan Rutin \\
\hline 7 & $0+600$ s.d $0+700$ & 93 & Pemeliharaan Rutin \\
\hline 8 & $0+700$ s.d $0+800$ & 89 & Pemeliharaan Rutin \\
\hline 9 & $0+800$ s.d $0+900$ & 70 & Rehabilitas \\
\hline 10 & $0+900$ s.d $1+000$ & 100 & Pemeliharaan Rutin \\
\hline 11 & $1+000$ s.d $1+250$ & 100 & Pemeliharaan Rutin \\
\hline
\end{tabular}

Dengan nilai PCI keseluruhan 987/11 = 89 sehingga jenis penanganan untuk ruas jalan Pemuda adalah pemeliharaan rutin dengan kondisi sangat baik (Excelent).

7) Ruas Jalan Puter dengan jarak ukur $130 \mathrm{~m}$. Pada setiap segmen dengan ukuran $100 \mathrm{~m} / \mathrm{segmen}$.

Tabel 14

Tabel jenis Pemeliharaan Jalan Puter

\begin{tabular}{cccc}
\hline No & STA & PCI & Jenis Pemeliharaan \\
\hline 1 & $0+000$ s.d $0+130$ & 28 & Rehabilitas \\
\hline
\end{tabular}

Dengan nilai PCI keseluruhan 28/1 = 28 sehingga jenis penanganan untuk ruas jalan Puter adalah pemeliharaan rehabilitas dengan kondisi rusak (Poor). 
5. Teknik Perbaikan dan Tingkat Kerusakan Jalan

Dalam melakukan penanganan pada tiap segmen kerusakan jalan maka harus sesuai dengan tingkat kerusakan jalan tersebut. Dalam metode PCI ini, memiliki tingkat kerusakan yaitu untuk menjadi acuan penangan kerusakan jalan.

Pavement Condition Index merupakan metode yang memiliki sistem rating penilaian untuk menyatakan kondisi kerusakan perkerasan jalan yang sesungguhnya. Maka dari itu, ada beberapa tingkat kerusakan jalan yaitu:

1) Excellent

Excellent merupakan kondisi kerusakan yang masih sempurna dengan nilai rating 100 yang menandakan tidak adanya kerusakan sampai dengan nilai rating 85 yang menandakan kerusakan hanya memerlukan pemeliharaan rutin.

2) Very Good

Very good ialah nilai kerusakan yang menandakan nilai tersebut merupakan nilai yang memiliki tingkat kerusakan ringan sehingga kerusakan tersebut hanya memerlukan tindakan pemeliharaan berkala. Dengan nilai rating 85 sampai dengan 70 .

3) Good

Good merupakan salah satu jenis tingkat kerusakan perkerasan jalan yang memiliki tingkat kerusakan ringan dan sedang sehingga jenis tingkat kerusakan tersebut memerlukan tindakan pemeliharaan rehabilitas. Dengan nilai rating 70 sampai dengan 55 .

4) Fair

Fair merupakan salah satu jenis tingkat kerusakan perkerasan jalan yang memiliki tingkat kerusakan sedang sehingga jenis tingkat kerusakan tersebut memerlukan tindakan pemeliharaan rehabilitas. Dengan nilai rating 55 sampai dengan 40.

5) Poor

Poor merupakan kondisi kerusakan yang cukup parah sehingga memerlukan pemeliharaan rehabilitas dengan nilai rating 40 sampai dengan nilai rating 25 yang menandakan kerusakan yang ada pada ruas jalan memiliki kerusakan yang sedang.

6) Very Poor

Very Poor merupakan salah satu jenis tingkat kerusakan perkerasan jalan yang memiliki tingkat kerusakan parah sehingga jenis tingkat kerusakan tersebut memerlukan tindakan pemeliharaan rekonstruksi. Dengan nilai rating 25 sampai dengan 10 .

7) Failed

Failed merupakan salah satu jenis tingkat kerusakan perkerasan jalan yang memiliki tingkat kerusakan yang sangat parah sehingga jenis tingkat kerusakan tersebut memerlukan tindakan pemeliharaan rekonstruksi. Dengan nilai rating 10 sampai dengan 0 . 
Pemeliharaan jalan merupakan suatu kegiatan yang dilakukan dengan cara pencegahan, perawatan jalan, perawatan jalan, dan perbaikan jalan. Yang dibutuhkan untuk mempertahankan kondisi jalan agar tetap berfungsi secara optimal untuk melayani lalu lintas sampai tercapainya nilai umur rencana yang telah ditetapkan. Untuk penilaian rating memiliki beberapa jenis tingkatan. 0-25 dapat melakukan penanganan rekonstruksi pada kerusakan jalan. 25-60 dapat melakukan penanganan rehabilitas pada kerusakan jalan. 60-80 dapat melakukan penanganan pemeliharaan berkala pada kerusakan jalan. Sedangkan 80-100 dapat melakukan penanganan dengan cara pemeliharaan rutin. Adapun beberapa jenis jalan dengan penanganan yang berbeda-beda yaitu:

1) Pemeliharaan Rutin

Pemeliharaan rutin merupakan kegiatan merawat serta memperbaiki kerusakan-kerusakan jalan yang terjadi pada ruas-ruas jalan dengan kondisi pelayana yang baik. Pemeliharaan rutin adalah pemeliharaan yang dilakukan sepanjang tahun dan sifatnya sebagai proteksi terhadap kerusakan yang lebih parah. Adanya jenis kegiatan pemeliharaan jalan rutin yaitu:

a) Lapisan permukaan, misalnya pelaburan aspal, penambalan lubang/patching, dan lain-lain.

b) Bahu jalan, antara lain pengisian material bahu jalan yang tergerus dan pemotongan rumput.

c) Drainase jalan, seperti pembersihan saluran agar tetap berfungsi saat musim hujan.

2) Pemeliharaan Berkala

Pemeliharaan berkala jalan adalah kegiatan penanganan pencegahan terjadinya kerusakan yang luas dan setiap kerusakan yang tidak diperhitungan dalam desain agar penurunan kondisi jalan dapat dikembalikan pada kondisi jalan yang baik sesuai dengan rencana.pemeliharaan berkala ini dilakukan pada waktu tertentu. Penanganan ini dilakukan pada kondisi jalan yang sudah menurun kualitas berkendaraannya sedangkan dengan upaya pemeliharaan rutin tidak dapat mengembalikan kondisi jalan dapat kondisi mantap. Oleh karena itu secara berkala dilakukan pelapisan ulang lapis permukaan agar jalan kembali pada kondisi mantap.

3) Rehabilitas

Rehabilitas Jalan adalah kegiatan penanganan pencegahan terjadinya kerusakan yang luas dan setiap kerusakan yang tidak diperhitungkan dalam desain, yang berakibat menurunnya kondisi yang baik pada bagian tempat tertentu dari suatu ruas jalan dengan kondisi rusak ringan, agar penurunan kondisi kemantapan tersebut dapat dikembalikan pada kondisi kemantapan yang sesuai dengan rencana.

4) Rekonstruksi

Rekonstruksi adalah penigkatan struktur yang merupakan kegiatan penanganan untuk dapat meningkatkan kemampuan bagian ruas jalan yang 
dalam kondisi rusak berat agar bagian jalan tersebut mempunyai kondisi mantap kembali sesuai dengan umur rencana yang ditetapkan.

Menurut buku pemeliharaan jalan raya (2007) menjelaskan hubungan antara metode PCI dan metode Bina Marga menurut buku pemeliharaan jalan raya (2007) adalah sebagai berikut:

Tabel 15

Hubungan PCI dan Bina marga

\begin{tabular}{cllc}
\hline 100 & Excellent & \\
\cline { 1 - 2 } 85 & Very Good & $\begin{array}{c}\text { Pemeliharaan } \\
\text { Rutin }\end{array}$ \\
\cline { 1 - 2 } 70 & Good & $\begin{array}{c}\text { Pemeliharaan } \\
\text { Berkala }\end{array}$ \\
\hline 55 & Fair & $\begin{array}{c}\text { Peningkatan } \\
\text { Jalan }\end{array}$ \\
\hline 25 & Poor & \\
\hline 10 & Very Poor & \\
\hline
\end{tabular}

Dari gambar diatas dapat dilihat bahwa PCI dengan nilai 0-40 pada bina marga berada pada peningkatan jalan, PCI dengan nilai 41-69 pada bina marga berada pada pemeliharaan berkala dan PCI 70-100 pada bina marga berada pada pemeliharaan rutin.

\section{Rencana Penanganan Kerusakan Jalan}

Kerusakan jalan merupakan kerusakan yang disebabkan oleh kelelahan akibat beban berulang-ulang. Umur rencana lima tahun umumnya yang diterapkan pada jalan baru. Jalan yang rusak karena beban biasanya disertai dengan jenis kerusakan amblas dan retak. Secara teknis, kerusakan jalan menunjukkan suatu kondisi dimana struktural dan fungsional jalan sudah tidak mampu memberikan pelayanan optimal terhadap terhadp lalu lintas yang melintasi jalan tersebut. Kondisi jalan dan jenis kendaraan mempengaruhi desain perencana konstruksi dan perkerasan jalan yang dibuat.

Menurut Heddy R. Agah, umumnya kerusakan jalan banyak disebabkan oleh perilaku pengguna jalan, kesalahan perencanaan dan pelaksanaan, serta pemeliharaan jalan yang tidak memadai.

1) Jenis Penanganan Kerusakan Jalan

a. Metode Perbaikan Kerusakan Jalan 
Metode pernbaikan kerusakan jalan pada lapisan lentur mengunakan metode standar Direktorat Jendral Bina Marga 1995. Jenis-jenis metode penanganan di tiap-tiap jenis kerusakan jalan yaitu:

a) Metode Perbaikan P1 (Penebaran Pasir)

Kerusakan ini untuk lokasi-lokasi kegemukan aspal terutama pada tikungan dan tanjakan. Langkah-langha untuk penanganannya yaitu memobilasi peralatan, kekerja dan material ke lapangan. Dan disetiap kerusakan tersebut ditandai. Lalu setelah ditandai maka daerah tersebut dibersihkan dengan menggunakan air compressor. Dan setelah membersihkan, maka dilakukan penyebaran agregat halus atau pasir kasar (tebal $>10 \mathrm{~mm}$ ) diatas permukaan yang terpengaruh kerusakan. Dan yang terakhir yaitu melakukan pemadatan dengan pemadat ringan (1-2) ton sampai diperoleh permukaan yang rata dan mempunyai kepadatan optimal (kepadatan 95\%)

b) Metode Perbaikan P2 (Pelaburan Aspal Setempat)

Jenis kerusakan yang ditangani adalah kerusakan tepi bahu jalan beraspal yaitu retak buaya $<2 \mathrm{~mm}$, retak garis kebar $<2 \mathrm{mmm}$ dan terkelupas. Langkah langkah yang akan dilakukan untuk penanganannya yaitu memobilisasi peralatan, pekerja dan material kelapangan. Selain itu, membersihkan bagian yang akan ditangani dengan air compressor, untuk permukaan jalan harus bersih dan kering. Setelah membersihkan maka dilakukan penyemprotan aspal keras sebanyak $1,5 \mathrm{~kg} / \mathrm{m} 2$ dan untuk cut back 1 liter/m2. Lalu menebarkan pasir kasar atau agregat halus $5 \mathrm{~mm}$ hingga rata. Dan yang terakhir yaitu melakukan pemadatan mesin pneumatic sampai dengan diperoleh permukaan yang rata dan mempunyai kepadatan optimal (kepadatan 95\%)

c) Metode Perbaikan P3 (Pelapisan Retakan)

Metode perbaikan jenis kerusakan yang ditangani yaitu retak satu arah dengan lebar retakan $<2 \mathrm{~mm}$. langkah langkah penanganan untuk kerusakan ini yaitu memobilitasi peralatan, pekerja dan material ke lapangan. Sebelum melakukan perbaikan yang akan dilakukan adalah membersihkan bagian yang akan ditangani dengan air compressor, sehingga permukaan jalan bersih dan kering. Tahap kedua, menyemprotkan tack coat ( 0,2 liter/m2 di daerah yang akan diperbaiki). Yang ketiga yaitu menebar dan meratakan campuran aspal beton pada seluruh daerah yang telah diberi tanda. Dan setelah itu melakukan pemadatan ringan (1-2) ton sampai diperoleh permukaan yang rata dan kepadatan optimum (kepadatan 95\%).

d) Metode Perbaikan P4 (Pengisian Retak)

Jenis kerusakan yang ditangani yaitu pada lokasi - lokasi retak satu arah dengan lebar retakan $>2 \mathrm{~mm}$. pada metode ini, langkah-langkah 
yang akan dilakukan untuk melakukan perbaikan jalan yaitu memobilisasikan peralatan, pekerja dan material ke lapangan. Setelah itu, jalan tersebut dibersihkan pada bagian yang akan ditangani dengan menggunakan air compressor, sehingga permukaan jalan bersih dan kering. Setelah itu mengisi retakan dengan aspal cut back 2 liter/m2 menggunakan aspal sprayer atau dengan tenaga manusia. Lalu menebarkan pasir kasar pada retakan yang telah diisi aspal dengan ketebalan 10mm. dan setelah itu, memadatkan minimal 3 lintasan dengan baby roller.

e) Metode Perbaikan P5 (Penambalan Lubang)

Jenis kerusakan pada jalan yang akan ditangani pada metode ini yaitu lubang kedalaman > 50mm, keriting kedalaman > 30mm, alur kedalaman $>50 \mathrm{~mm}$, amblas kedalaman $>50 \mathrm{~mm}$, jembul kedalaman > $50 \mathrm{~mm}$, kerusakan tepi perkerasan jalan, dan retak buaya dengan lebar > $2 \mathrm{~mm}$. pada jenis - jenis kerusakan jalan tersebut maka akan dilakukan pada langkah-langkah untuk penanganannya yaitu menggali material sampai dengan lapisan dibawahnya. Setelah itu, membersihkan bagian yang akan ditangani dengan tenaga manusia. Lalu menyemprot lapis resap pengikat prime coat dengan takaran 0,5 liter/m2. Menyebarkan dan memadatkan capuran aspal beton sampai diperoleh permukaan yang rata. Dan memadatkan dengan baby roller (minimal 5 lintasan)

f) Metode Perbaikan P6 (Peralatan)

Jensi kerusakan yang ditangani yaitu keriting dalam dengan kedalaman $<30 \mathrm{~mm}$, lubang dengan kedalaman $<50 \mathrm{~mm}$, jembul dengan kedalaman $<50 \mathrm{~mm}$. Pada jnis kerusakan tersebut akan dilakukan penanganan, pertama membersihkan bagian yang akan di tangani dengan tenaga manusia. Kedua melaburkan tack coat 0,5 liter/m2. Ketiga, menaburkan campuran aspal beton kemudian memadatkannya dengan sampai diperoleh permukaan yang rata. Dan setelah itu, pemadatan dengan baby roller (minimum 5 lintasan).

\section{Kesimpulan}

Jenis dan tingkat kerusakan pada ruas jalan tersebut adalah Patching memiliki 55 $\%$, Potholes memiliki 34\%, Alligator Cracking memiliki 7\%, Block craking memiliki 5\%, LT Cracking memiliki 3\%, Depresion memiliki 3\%.

Persentase Jenis penanganan yang diperlukan sesuai dengan tingkat kerusakan jalan diantaranya Pemeliharaan rutin 43\%, Pemeliharaan berkala 29\%, Pemeliharaan rehabilitas $14 \%$ dan Pemeliharaan Rekontruksi $14 \%$. 


\section{BIBLIOGRAFI}

Evitya, Dwi Lestari, Nasfryzal, Carlo, \& Zufrimar, Zufrimar. (2020). Analisis Kerusakan Perkerasan Jalan Dengan Metode Pavement Condition Index (PCI) Dan Bina Marga (Ruas Jalan Sijunjung STA 103+ 000-108+ 000). Universitas Bung Hatta. Google Scholar

Giyatno, Giyatno, \& Sunarjono, Ir Sri. (2016). Analisis Kerusakan Jalan Dengan Metode PCI Kajian Ekonomis Dan Strategi Penanganannya (Studi Kasus Ruas Jalan Ponorogo-Pacitan KM 231+ 000 Sampai Dengan KM 246+ 000, KM O+ 000 Di Surabaya). Universitas Muhammadiyah Surakarta. Google Scholar

Hasibuan, Dede Sahbana. (2018). Analisa Kerusakan pada Lapisan Jalan Perkerasan Rigid dengan Metode Bina Marga dan Metode PCI (Pavement Condition Index). Google Scholar

Mubarak, Husni. (2016). Analisa Tingkat Kerusakan Perkerasan Jalan Dengan Metode Pavement Condition Index (Pci) Studi Kasus: Jalan Soekarno Hatta Sta. 11+ 150 sd 12+ 150. Jurnal Saintis, 16(1), 94-109. Google Scholar

Sari, Devita. (2015). Perbandingan Nilai Kerusakan Jalan Berdasarkan Pengamatan Metode Pci (Pavement Condition Index) Dan Metode Iri (International Roughness Index) Pada Jalan Kelas II Di Kabupaten Lumajang. Google Scholar

\section{Copyright holder:}

Dian Setiawan, Heri Suprapto (2021)

First publication right:

Syntax Literate: Jurnal Ilmiah Indonesia

This article is licensed under:

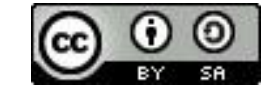

